\title{
Functionalized $\mathrm{NbS}_{2}$ as cathode for $\mathrm{Li}$ - and $\mathrm{Na}$-ion batteries
}

Jiajie Zhu, Husam N. Alshareef, and Udo Schwingenschlögl

Citation: Appl. Phys. Lett. 111, 043903 (2017); doi: 10.1063/1.4985694

View online: http://dx.doi.org/10.1063/1.4985694

View Table of Contents: http://aip.scitation.org/toc/apl/111/4

Published by the American Institute of Physics

\section{Articles you may be interested in}

In-plane magnetic anisotropy of the $\mathrm{Sr}_{4} \mathrm{Ru}_{3} \mathrm{O}_{10}$ nanosheet probed by planar Hall effect

Applied Physics Letters 111, 033103 (2017); 10.1063/1.4993936

Single-photon emission at $1.55 \mu \mathrm{m}$ from MOVPE-grown InAs quantum dots on InGaAs/GaAs metamorphic buffers

Applied Physics Letters 111, 033102 (2017); 10.1063/1.4993935

Multi-frequency spin manipulation using rapidly tunable superconducting coplanar waveguide microresonators Applied Physics Letters 111, 032601 (2017); 10.1063/1.4993930

Strong dopant dependence of electric transport in ion-gated $\mathrm{MoS}_{2}$

Applied Physics Letters 111, 013106 (2017); 10.1063/1.4992477

Anomalous Seebeck coefficient observed in silicon nanowire micro thermoelectric generator Applied Physics Letters 111, 023105 (2017); 10.1063/1.4993150

Enhanced radiative emission from monolayer $\mathrm{MoS}_{2}$ films using a single plasmonic dimer nanoantenna Applied Physics Letters 111, 031101 (2017); 10.1063/1.4993427

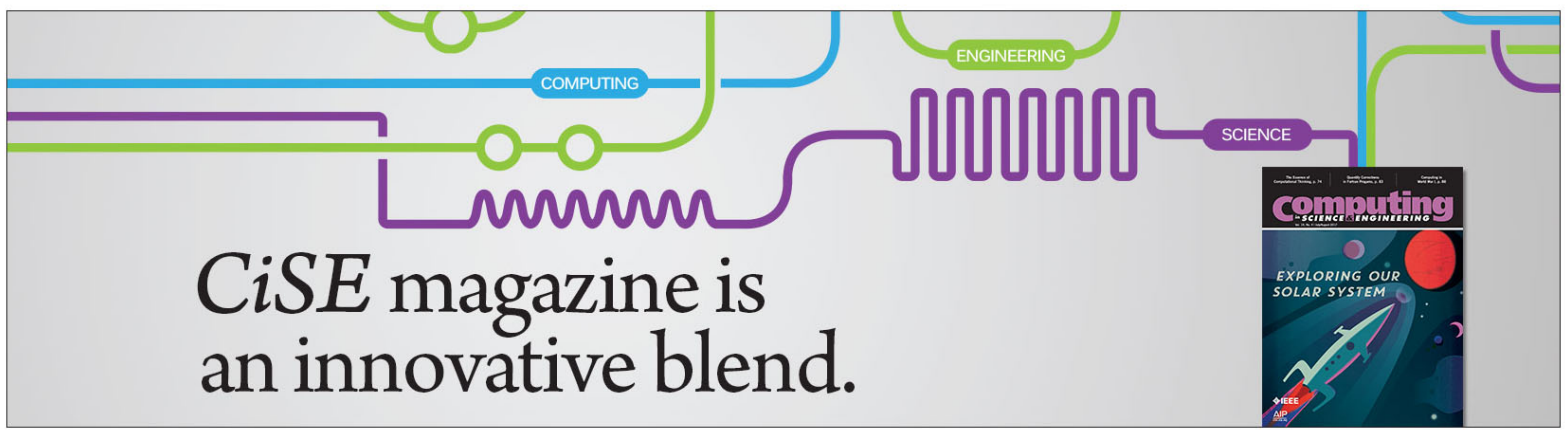




\title{
Functionalized $\mathrm{NbS}_{2}$ as cathode for $\mathrm{Li}$ - and $\mathrm{Na}$-ion batteries
}

\author{
Jiajie Zhu, ${ }^{1,2}$ Husam N. Alshareef, ${ }^{2}$ and Udo Schwingenschlögl ${ }^{2, a)}$ \\ ${ }^{1}$ College of Materials Science and Engineering, Shenzhen University, Nanhai Ave 3688, ShenZhen, \\ Guangdong 518060, People's Republic of China \\ ${ }^{2}$ King Abdullah University of Science and Technology (KAUST), Physical Science and Engineering Division (PSE), \\ Thuwal 23955-6900, Saudi Arabia
}

(Received 1 June 2017; accepted 18 July 2017; published online 27 July 2017)

Cathodes of Li- and Na-ion batteries usually have capacities $<200 \mathrm{mAh} / \mathrm{g}$, significantly less than the anodes. Two-dimensional materials can overcome this limitation but suffer from low voltages. In this context, we investigate $\mathrm{NbS}_{2}$ functionalized by $\mathrm{O}, \mathrm{F}$, and $\mathrm{Cl}$ as a cathode material by firstprinciples calculations, considering both the conversion and intercalation mechanisms. $\mathrm{NbS}_{2} \mathrm{O}_{2}$ shows a higher voltage than $\mathrm{NbS}_{2}$ for both $\mathrm{Li}$ and $\mathrm{Na}$, but the voltage decreases drastically for increasing ion coverage. Even higher voltages and favorable dependences on the ion coverage are achieved by $\mathrm{F}$ and $\mathrm{Cl}$ functionalization. We obtain $\mathrm{NbS}_{2} \mathrm{~F}_{2}$ and $\mathrm{NbS}_{2} \mathrm{Cl}_{2}$ energy densities of $1223 \mathrm{~mW} \mathrm{~h} / \mathrm{g}$ and $823 \mathrm{~mW} \mathrm{~h} / \mathrm{g}$ for lithiation and $1086 \mathrm{~mW} \mathrm{~h} / \mathrm{g}$ and $835 \mathrm{~mW} \mathrm{~h} / \mathrm{g}$ for sodiation, respectively. These values are higher than those for most state-of-the-art cathode materials ( $\sim 600 \mathrm{~mW} \mathrm{~h} / \mathrm{g})$. In addition, low diffusion barriers enable high cycling rates. Published by AIP Publishing.

[http://dx.doi.org/10.1063/1.4985694]

Nowadays, batteries, fuel cells, and supercapacitors are attracting much attention as energy storage and conversion devices, motivated by a rapidly increasing global energy consumption. Rechargeable Li-ion batteries, using $\mathrm{Li}$ ions for the charge transfer, are replacing lead-acid, $\mathrm{Ni}-\mathrm{Cd}$, and nickel-metal-hydride batteries because of environmental concerns due to the toxic metals. A high energy density, the absence of memory effects, and a long cycle life enable Liion batteries to be widely used in portable electronic devices such as cell phones, laptops, and cameras. ${ }^{1,2}$ However, scarcity and associated high costs of Li limit its field of applications. Na-ion batteries have been considered as promising alternatives in large scale devices, such as electric vehicles and power grids, since their properties are similar and $\mathrm{Na}$ has the advantage of natural abundance. ${ }^{3}$

The anode and cathode materials used in commercial Li-ion batteries are graphite and transition metal oxides, respectively, with the operation being based on the intercalation mechanism. ${ }^{4}$ Since graphite has a low theoretical capacity of $372 \mathrm{~mA} \mathrm{~h} / \mathrm{g},{ }^{5}$ various alternatives with capacities $>600$ $\mathrm{mAh} / \mathrm{g}$ have been proposed, including $\mathrm{SnO}_{2},{ }^{6}$ graphene, ${ }^{7}$ and silicene. ${ }^{8}$ Phosphorene has been put forward as a high capacity anode material for Na-ion batteries. ${ }^{9,10}$ The operational voltages of most cathode materials for Li-ion batteries range from $3 \mathrm{~V}$ to $4 \mathrm{~V}$ with an energy density (product of voltage and capacity) of some $600 \mathrm{mWh} / \mathrm{g}$, rarely reaching $900 \mathrm{mWh} / \mathrm{g}{ }^{11}$ Similar limitations of the energy density apply to Na-ion batteries. ${ }^{12}$ Since the typical cathode capacity is $<200 \mathrm{mAh} / \mathrm{g}$, i.e., significantly lower than that of the anode, and the voltage is bound by the stability limit of the electrolyte (usually $4.6 \mathrm{~V}$ ), ${ }^{11,12}$ it is effective to improve the energy density by enhancing the capacity.

Two-dimensional materials have been predicted to provide high $\mathrm{Li}$ and $\mathrm{Na}$ capacities as anodes due to their large surface areas. ${ }^{13,14}$ In addition, low diffusion barriers (flat

\footnotetext{
a)Email: udo.schwingenschlogl@kaust.edu.sa
}

potential surfaces) enable high cycling rates. ${ }^{15,16}$ However, weak interactions with ions lead to low and decreasing voltages in the intercalation reactions, which limits their application as cathodes. ${ }^{17,18}$ Electrodes employing conversion mechanisms usually yield higher voltages. ${ }^{4}$ On the other hand, it is known from MXenes that functionalization can be used to tailor the surface properties of two-dimensional materials, in particular the interaction with ions. ${ }^{19,20}$ Monolayer transition metal dichalcogenides, which can be exfoliated from bulk crystals, ${ }^{21}$ are semiconducting when they are based on $\mathrm{Mo}$ and $\mathrm{W}$, whereas $\mathrm{NbS}_{2}$ is a metallic member of the family and therefore interesting from the battery point of view. Indeed, bulk $\mathrm{NbS}_{2}$ has been considered as an anode in $\mathrm{Na}$-ion batteries, providing a voltage below $1 \mathrm{~V}^{22} \mathrm{We}$ study in the present work the potential of monolayer $\mathrm{NbS}_{2}$ functionalized by $\mathrm{O}, \mathrm{F}$, and $\mathrm{Cl}$ (chosen because of the high electronegativities $^{23}$ ) as a cathode material for $\mathrm{Li}$ - and $\mathrm{Na}$-ion batteries, considering both the conversion and intercalation mechanisms.

Lithiation and sodiation of monolayer $\mathrm{NbS}_{2}$ are investigated using $2 \times 2$ in-plane supercells with a vacuum layer of $15 \AA$ thickness in the out-of-plane direction to enable the application of three-dimensional periodic boundary conditions. Total energy calculations are carried out in the framework of the density functional theory and the projector augmented wave method, as implemented in the Vienna Ab-initio Simulation Package. ${ }^{24}$ The exchange correlation potential is modeled in the generalized gradient approximation of Perdew, Burke, and Ernzerhof. ${ }^{25}$ In addition, the long-range van der Waals interaction is taken into account by means of the DFT-D3 approach. ${ }^{26}$ The cut-off energy of the plane wave basis is set to $500 \mathrm{eV}$ and the energy criterion of the iterative solution of the Kohn-Sham equations to $10^{-6} \mathrm{eV}$. All structures are relaxed until the residual forces on the atoms have declined to less than $0.01 \mathrm{eV} / \AA$. Brillouin zone integrations are performed on a $6 \times 6 \times 1 \mathrm{k}$-mesh. All the technical parameters have been tested carefully for convergence. The nudged elastic band method ${ }^{27}$ with 9 images 
between the initial and final states is employed to evaluate the diffusion paths and barriers.

The in-plane lattice constant of H-phase ${ }^{16} \mathrm{NbS}_{2}$ is calculated to be $3.33 \AA$, in good agreement with the experimental value of $3.31 \AA^{22} \mathrm{O}, \mathrm{F}$, and $\mathrm{Cl}$ functionalization modifies it to $3.28 \AA, 3.45 \AA$, and $3.48 \AA$, being stable with negative formation energies of $-0.86 \mathrm{eV},-1.39 \mathrm{eV}$, and $-0.03 \mathrm{eV}$, respectively. We note that these values are modified by less than $0.01 \mathrm{eV}$ when the vdWB86b functional is used instead of the DFT-D3 approach. Formation energies, $\Delta H$, here and in the following are defined as differences between the total energy of a combined system and the sum of the total energies of its parts. Since the absolute value is very small for $\mathrm{Cl}$ functionalization, we have confirmed the stability by $a b$-initio molecular dynamics simulations for $4 \mathrm{ps}$ at $300 \mathrm{~K}$. This result is also supported by the fact that $\mathrm{NbS}_{2} \mathrm{Cl}_{2}$ has been prepared experimentally in Ref. 28. In addition, ab-initio molecular dynamics simulations exclude the reaction of $\mathrm{Li} / \mathrm{Na}$ with $\mathrm{NbS}_{2}$ and structural collapse during lithiation and sodiation. Comparison to the T-phase ${ }^{16}$ shows for all functionalizations and coverages considered in this study that the $\mathrm{H}$-phase is favorable. The S-O (1.48 $)$, S-F (1.69 $\AA$ ), and S-Cl ( $2.13 \AA)$ bond lengths are influenced by both the charge transfer and the ionic radius.

Figure 1 shows the structures of $\mathrm{NbS}_{2} \mathrm{O}_{2}$ decorated with $\mathrm{Li} / \mathrm{Na}$ on top of the (a) $\mathrm{Nb}$ and (b) hollow sites. These two configurations turn out to be energetically almost degenerate for low $\mathrm{Li} / \mathrm{Na}$ coverage, while decoration on top of the $\mathrm{O} / \mathrm{F} /$ $\mathrm{Cl}$ site results in significantly higher total energy. For high $\mathrm{Li} / \mathrm{Na}$ coverage, on the other hand, decoration on top of the $\mathrm{Nb}$ site is found to be favorable. We note that decoration on top of the bridge site always results in relaxation toward configuration (a). The perpendicular distance between $\mathrm{Li} / \mathrm{Na}$ and O relaxes to $0.75 / 1.11 \AA$, mostly determined by the ionic radius of $\mathrm{Li} / \mathrm{Na}$, and negative formation energy associated with the decoration $(-4.23 /-3.95 \mathrm{eV})$ reflects stability. For bare $\mathrm{NbS}_{2}$, this formation energy amounts to $-2.03 /-1.80 \mathrm{eV}$. Since the Coulomb interaction determines the stability, we summarize the charge transfers obtained from Bader atomic charges in Table I. Mainly, S and O are affected by charge transfer due to the presence of $\mathrm{Li} / \mathrm{Na}$. This effect is also (a)
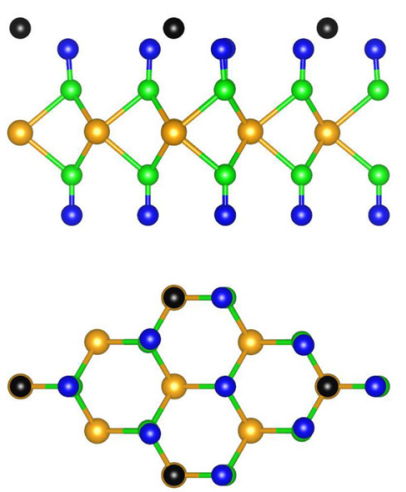

(b)
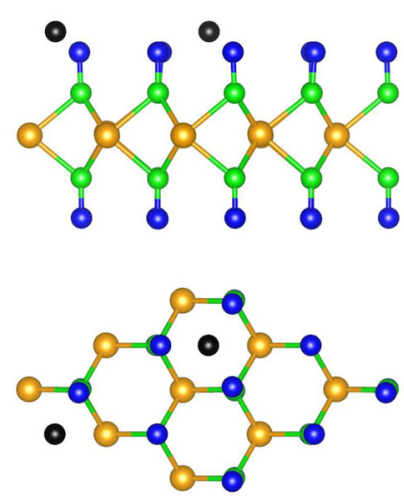

FIG. 1. Side and top views of $\mathrm{NbS}_{2} \mathrm{O}_{2}$ decorated with $\mathrm{Li} / \mathrm{Na}$ on top of the (a) $\mathrm{Nb}$ and (b) hollow sites. $\mathrm{Nb}, \mathrm{S}, \mathrm{O}$, and $\mathrm{Li} / \mathrm{Na}$ atoms are shown in light brown, green, blue, and black color, respectively.
TABLE I. Charge transfers affecting $\mathrm{Nb}, \mathrm{S}, \mathrm{O}$, and $\mathrm{Li} / \mathrm{Na}$ in $\mathrm{NbS}_{2}: \mathrm{Li} / \mathrm{Na}$ and $\mathrm{NbS}_{2} \mathrm{O}_{2}: \mathrm{Li} / \mathrm{Na}$ (obtained from Bader charges). Positive and negative values represent the charge depletion and accumulation, respectively.

\begin{tabular}{lcccc}
\hline \hline & $\mathrm{Nb}$ & $\mathrm{S}$ & $\mathrm{O}$ & $\mathrm{Li} / \mathrm{Na}$ \\
\hline $\mathrm{NbS}_{2}$ & +1.58 & -0.79 & $\ldots$ & $\ldots$ \\
$\mathrm{NbS}_{2}: \mathrm{Li}$ & +1.51 & -0.98 & $\ldots$ & +0.86 \\
$\mathrm{NbS}_{2}: \mathrm{Na}$ & +1.55 & -0.96 & $\ldots$ & +0.82 \\
$\mathrm{NbS}_{2} \mathrm{O}_{2}$ & +1.22 & +0.35 & -0.96 & $\ldots$ \\
$\mathrm{NbS}_{2} \mathrm{O}_{2}: \mathrm{Li}$ & +1.24 & +0.20 & -1.09 & +0.88 \\
$\mathrm{NbS}_{2} \mathrm{O}_{2}: \mathrm{Na}$ & +1.24 & +0.18 & -1.04 & +0.86 \\
\hline \hline
\end{tabular}

visible in Fig. 2 just above the Fermi energy by a reduction in the $\mathrm{S} 3 p$ and $\mathrm{O} 2 p$ densities of states. Both before and after $\mathrm{Li} / \mathrm{Na}$ decoration, the system is metallic, with $\mathrm{Nb} 4 d$ (dominating), $\mathrm{S} 3 p$, and $\mathrm{O} 2 p$ contributions at the Fermi energy.

In order to evaluate whether $\mathrm{NbS}_{2} \mathrm{O}_{2}$ can provide the high voltage required by a cathode material, the voltage ${ }^{29}$

$$
V=\frac{E\left[x_{2}\right]-E\left[x_{1}\right]-\left(x_{2}-x_{1}\right) \cdot E[\mathrm{Li} / \mathrm{Na}]}{x_{2}-x_{1}},
$$

with respect to bulk $\mathrm{Li} / \mathrm{Na}$ (where $E$ is the total energy and $x$ the $\mathrm{Li} / \mathrm{Na}$ coverage) is addressed in Fig. 3 for different reaction mechanisms. The conversion reaction

$$
\mathrm{NbS}_{2} \mathrm{O}_{2}+2 \mathrm{z} \cdot \mathrm{Li}=\mathrm{NbS}_{2} \mathrm{O}_{2-\mathrm{z}}+\mathrm{z} \cdot \mathrm{Li}_{2} \mathrm{O},
$$

yields almost flat voltages of $2.8 \mathrm{~V}$ and $1.9 \mathrm{~V}$ for lithiation and sodiation, respectively. The voltages obtained for the intercalation reaction

$$
\mathrm{NbS}_{2} \mathrm{O}_{2}+\mathrm{z} \cdot \mathrm{Li}=\mathrm{NbS}_{2} \mathrm{O}_{2} \mathrm{Li}_{\mathrm{z}}
$$

initially are much higher, $4.2 \mathrm{~V}$ and $3.9 \mathrm{~V}$, but decrease fast due to the repulsion between the $\mathrm{Li} / \mathrm{Na}$ ions, reaching values of $1.8 \mathrm{~V}$ and $1.1 \mathrm{~V}$ at a coverage of 2 ions per $\mathrm{NbS}_{2} \mathrm{O}_{2}$ unit

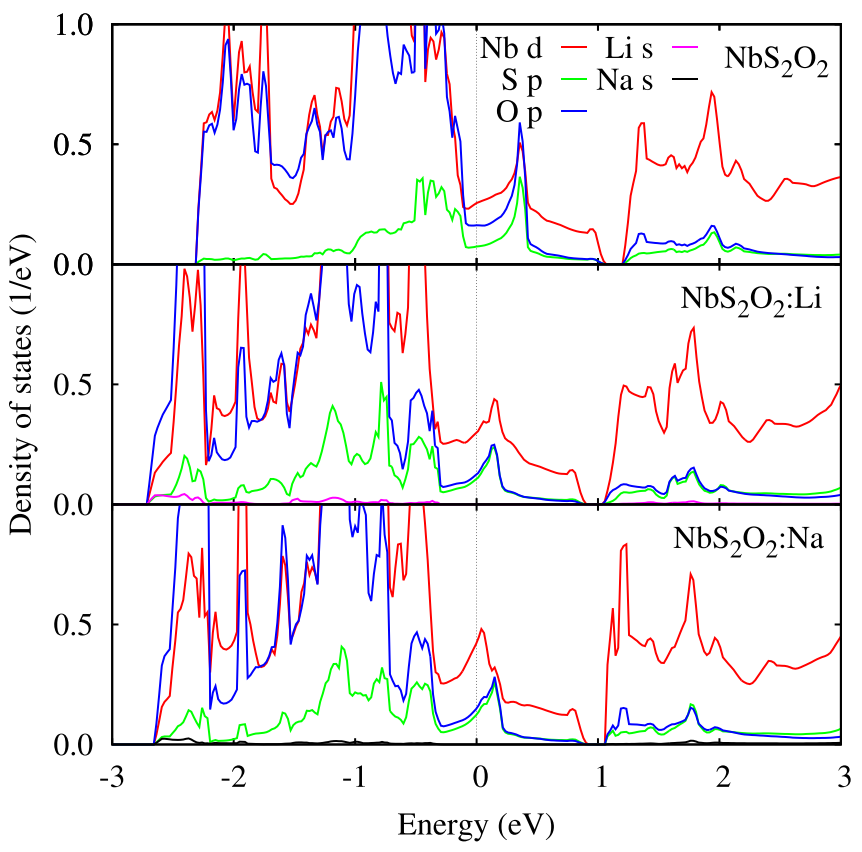

FIG. 2. Partial densities of states of $\mathrm{NbS}_{2} \mathrm{O}_{2}$ and $\mathrm{NbS}_{2} \mathrm{O}_{2}: \mathrm{Li} / \mathrm{Na}$. The energy zero is the Fermi energy. 


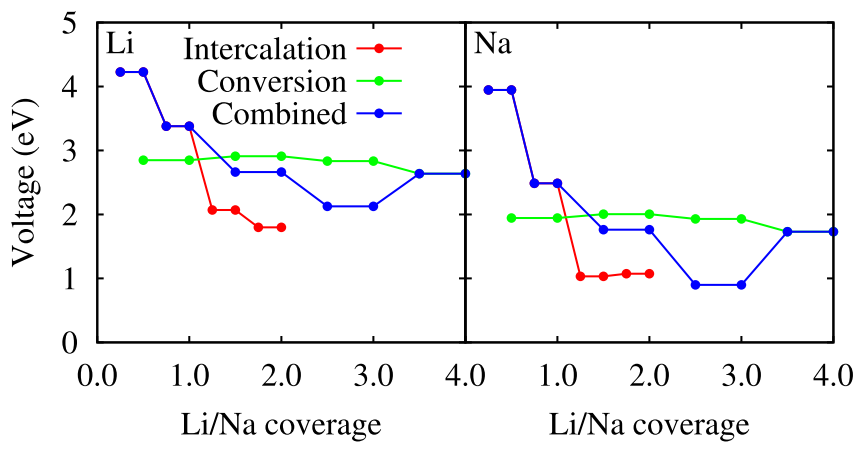

FIG. 3. Voltage for $\mathrm{NbS}_{2} \mathrm{O}_{2}$ as a function of the $\mathrm{Li} / \mathrm{Na}$ coverage.

cell. Turning to the combination of the two mechanisms, we assume that $\mathrm{Li} / \mathrm{Na}$ is located near $\mathrm{O}$, as we have shown before that the formation energy is much less negative for $\mathrm{NbS}_{2}$ than for $\mathrm{NbS}_{2} \mathrm{O}_{2}$. When the coverage is not more than 1 , then the removal of intercalated $\mathrm{Li} / \mathrm{Na}$ and $\mathrm{O}$ is endothermic, reflecting stability, while conversion becomes exothermic for higher coverage. However, the voltage obtained for the combined reactions is lower than that obtained for pure conversion, see Fig. 3, because $\mathrm{O}$ needs to overcome the interaction with other ions. The required value of about $3 \mathrm{~V}$ is achieved only for low coverage.

In order to improve the voltage, we replace different amounts of $\mathrm{O}$ with $\mathrm{F}$ or $\mathrm{Cl}$. $\mathrm{F}$ has a higher electronegativity than $\mathrm{O}$, and $\mathrm{Cl}$ can be easily removed from $\mathrm{NbS}_{2}$ (formation energy close to zero, see above). Figure 4 shows the voltages for $\mathrm{NbS}_{2}\left(\mathrm{O}_{1-x} \mathrm{~F}_{x}\right)_{2}$ and $\mathrm{NbS}_{2}\left(\mathrm{O}_{1-x} \mathrm{Cl}_{x}\right)_{2}$ for $0 \leq x \leq 1$. Conversion of $\mathrm{F}$ is always more exothermic than intercalation, which leads to the complete removal of $\mathrm{F}$ before intercalation begins. A similar behavior is found for $\mathrm{Cl}$, except for $x=0.25$ where $\mathrm{Cl}$ is converted after two Li/Na ions have been intercalated near $\mathrm{O}$ atoms. The lithiation and sodiation voltages of $\mathrm{NbS}_{2} \mathrm{~F}_{2}$ range from $4.4 \mathrm{~V}$ to $5.2 \mathrm{~V}$ and from $3.9 \mathrm{~V}$

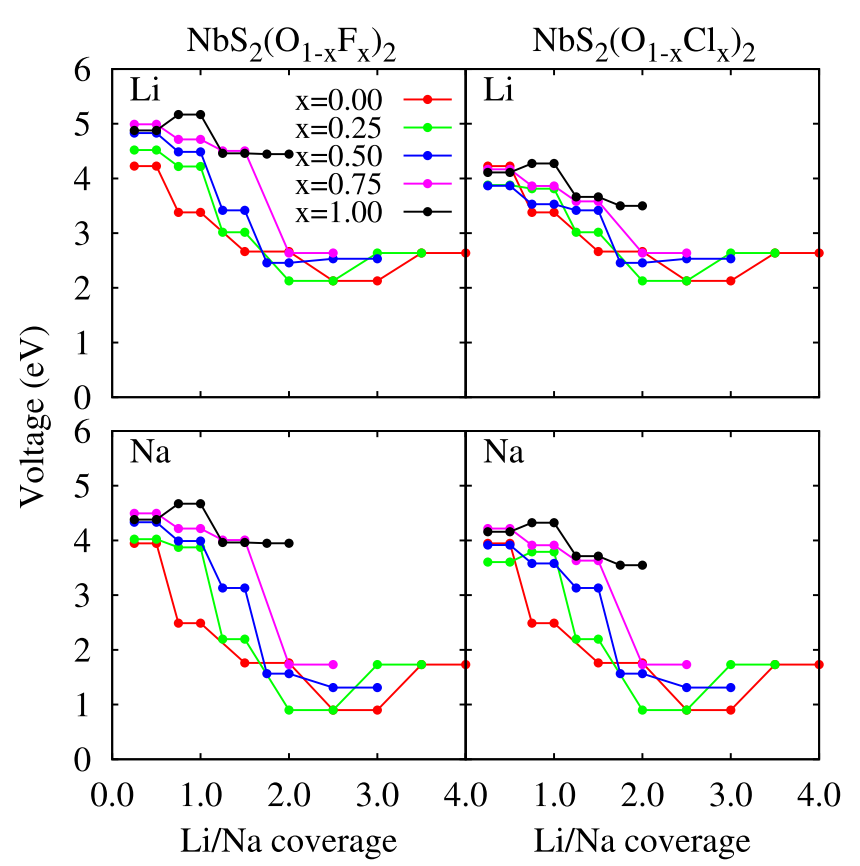

FIG. 4. Voltages for $\mathrm{NbS}_{2}\left(\mathrm{O}_{1-x} \mathrm{~F}_{x}\right)_{2}$ and $\mathrm{NbS}_{2}\left(\mathrm{O}_{1-x} \mathrm{Cl}_{x}\right)_{2}$ as functions of the $\mathrm{Li} / \mathrm{Na}$ coverage. to $4.7 \mathrm{~V}$, respectively, being higher than in the case of $\mathrm{NbS}_{2} \mathrm{Cl}_{2}$ (from $3.5 \mathrm{~V}$ to $4.3 \mathrm{~V}$ ) due to more negative cohesive energies of $\mathrm{LiF} / \mathrm{NaF}(-4.56 /-4.08 \mathrm{eV})$ as compared to those of $\mathrm{LiCl} / \mathrm{NaCl}(-3.55 /-3.34 \mathrm{eV})$. As compared to $\mathrm{NbS}_{2} \mathrm{O}_{2}$, the voltages are much higher, while the maximal coverage is much smaller. In addition, the lowest observed voltages increase with $x$ for both $\mathrm{F}$ and $\mathrm{Cl}$, see Fig. 4. After $\mathrm{F} / \mathrm{Cl}$ is completely converted, the voltages equal those of $\mathrm{NbS}_{2} \mathrm{O}_{2}$. We note that the generalized gradient approximation ${ }^{25}$ usually underestimates the calculated voltages. ${ }^{30}$ Improved descriptions of the exchange correlation potential would predict even better battery performance for functionalized $\mathrm{NbS}_{2}$. ${ }^{31,32}$

Figure 5 shows for $\mathrm{NbS}_{2}\left(\mathrm{O}_{1-x} \mathrm{~F}_{x}\right)_{2}$ and $\mathrm{NbS}_{2}\left(\mathrm{O}_{1-x} \mathrm{Cl}_{x}\right)_{2}$ for $0 \leq x \leq 1$ the energy density calculated as a product of the lowest voltage that still exceeds the $3 \mathrm{~V}$ threshold and the capacity, $C=x \cdot F / M$, where $F$ is the Faraday constant and $M$ is the atomic mass. ${ }^{29}$ The obtained capacities exceed that of the commercial cathode $\mathrm{LiCoO}_{2}$, for example, Ref. 11. The energy densities increase significantly with $x$, exceeding for lithiation and sodiation the $\sim 600 \mathrm{mWh} / \mathrm{g}$ threshold of most state-of-the-art cathode materials for $x>0.25$ and 0.50 , respectively. Energy densities of $1223 \mathrm{mWh} / \mathrm{g}$ (F functionalization) and $823 \mathrm{mWh} / \mathrm{g}$ ( $\mathrm{Cl}$ functionalization) can be achieved for lithiation, while for sodiation, the corresponding values are $1086 \mathrm{~mW} \mathrm{~h} / \mathrm{g}$ and $835 \mathrm{mWh} / \mathrm{g}$. According to Ref. $28, \mathrm{NbS}_{2} \mathrm{Cl}_{2}$ cathodes for Na-ion batteries provide an open circuit voltage of $3.2 \mathrm{~V}$, a capacity of $120 \mathrm{~mA} \mathrm{~h} / \mathrm{g}$, and an energy density of $320 \mathrm{mWh} / \mathrm{g}$. Deviations of the capacity and energy density from the theoretical values are due to the lower experimental voltage of $3.6 \mathrm{~V}$. Since $\mathrm{NbS}_{2} \mathrm{Cl}_{2}$ exists, $\mathrm{NbS}_{2}$ in principle can be functionalized by $\mathrm{O}$ and $\mathrm{F}$ due to higher electronegativities as compared to $\mathrm{Cl}$.

The diffusion paths and barriers are shown in Fig. 6, as they determine the cycling performance. We compare two diffusion paths connecting $\mathrm{Li} / \mathrm{Na}$ on top of a $\mathrm{Nb}$ site (ground

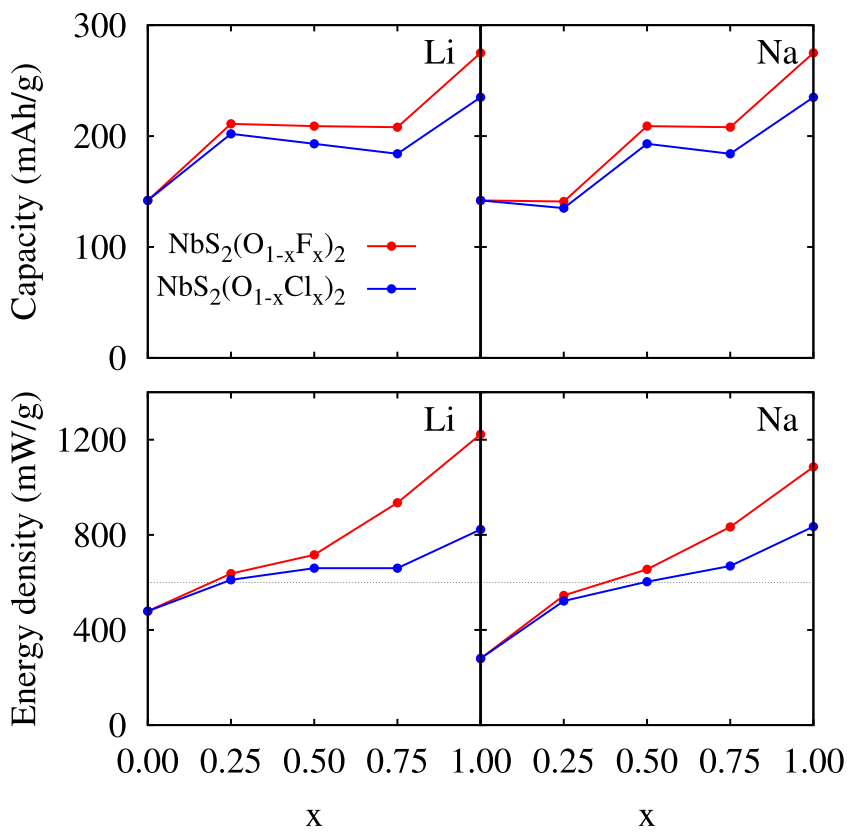

FIG. 5. Capacities and energy densities for $\mathrm{NbS}_{2}\left(\mathrm{O}_{1-x} \mathrm{~F}_{x}\right)_{2}$ and $\mathrm{NbS}_{2}\left(\mathrm{O}_{1-x} \mathrm{Cl}_{x}\right)_{2}$ in the cases of lithiation and sodiation. The dashed line represents the typical energy density of state-of-the-art cathode materials. 

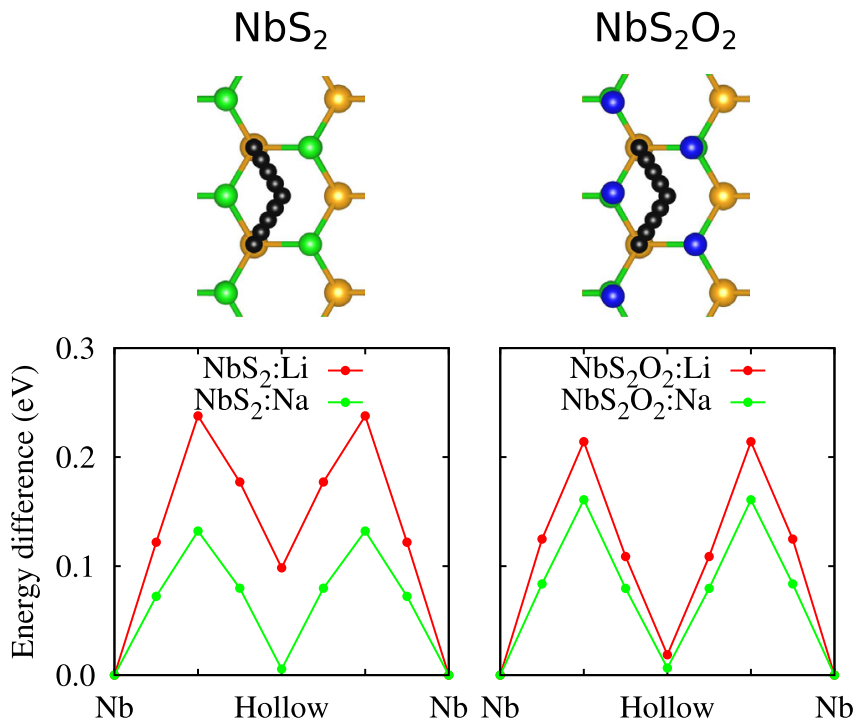

FIG. 6. Diffusion paths and barriers for $\mathrm{NbS}_{2}$ and $\mathrm{NbS}_{2} \mathrm{O}_{2}$. The $\mathrm{Nb}, \mathrm{S}, \mathrm{O}$, and $\mathrm{Li} / \mathrm{Na}$ atoms are shown in light brown, green, blue, and black color.

state) with the nearest equivalent site for both $\mathrm{NbS}_{2}$ and $\mathrm{NbS}_{2} \mathrm{O}_{2}$. Path $\mathrm{A}$ passes through the top of the hollow site, while path $\mathrm{B}$ is a straight connection. It turns out that path $\mathrm{B}$ always converges to path $\mathrm{A}$. On $\mathrm{NbS}_{2}$, we obtain diffusion barriers of $0.24 \mathrm{eV}$ and $0.13 \mathrm{eV}$ (in agreement with the theoretical value of Ref. 22) for $\mathrm{Li}$ and $\mathrm{Na}$, respectively. The corresponding values on $\mathrm{NbS}_{2} \mathrm{O}_{2}$ are $0.21 \mathrm{eV}$ and $0.16 \mathrm{eV}$. The interaction of $\mathrm{Na}$ with $\mathrm{O}$ increases the diffusion barrier as compared to bare $\mathrm{NbS}_{2}$, while for $\mathrm{Li}$, this effect is overcompensated by an enhanced height of the diffusion path after $\mathrm{O}$ functionalization. We note that the transition points are located at about one and three quarters of the diffusion path. The calculated Li diffusion barriers are comparable with the low values of other two-dimensional materials, including silicene [0.23 eV (Ref. 8)] and $\mathrm{MoS}_{2}[0.21 \mathrm{eV}$ (Ref. 16)].

$\mathrm{NbS}_{2}$ functionalized by $\mathrm{O}, \mathrm{F}$, and $\mathrm{Cl}$ has been investigated by first-principles calculations as a potential cathode material for $\mathrm{Li}$ - and $\mathrm{Na}$-ion batteries, considering both the conversion and intercalation mechanisms. Intercalated $\mathrm{Li} / \mathrm{Na}$ ions turn out to be more strongly bound on $\mathrm{NbS}_{2} \mathrm{O}_{2}$ than $\mathrm{NbS}_{2}$, which leads to a higher open circuit voltage. However, the voltage provided by $\mathrm{NbS}_{2} \mathrm{O}_{2}$ decreases drastically with the $\mathrm{Li} / \mathrm{Na}$ coverage due to repulsion between the intercalated ions. The replacement of $\mathrm{O}$ with $\mathrm{F}$ or $\mathrm{Cl}$ improves the voltage due to modified conversion reactions, and this effect is found to be enhanced for increasing $\mathrm{Li} / \mathrm{Na}$ coverage. In addition, $\mathrm{F}$ and $\mathrm{Cl}$ are predicted to provide almost constant voltages for low coverage. Lithiation and sodiation energy densities of $1223 \mathrm{mWh} / \mathrm{g}$ and $1086 \mathrm{mWh} / \mathrm{g}$ are obtained for $\mathrm{NbS}_{2} \mathrm{~F}_{2}$ and $823 \mathrm{mWh} / \mathrm{g}$ and $835 \mathrm{mWh} / \mathrm{g}$ for $\mathrm{NbS}_{2} \mathrm{Cl}_{2}$, respectively, outperforming most current cathode materials. The diffusion barriers are found to be favorably low to enable high cycling rates. In contrast to $\mathrm{Cl}$ functionalization, $\mathrm{F}$ functionalization in the case of lithiation can result in voltages beyond the current electrolyte safety limit $(4.6 \mathrm{~V})$, calling for the design of alternative electrolytes. In summary, our study demonstrates how the applicability of transition metal dichalcogenides in
Li- and Na-ion batteries can be extended to cathodes. The observed enhancement of the energy density opens urgently needed avenues for improving the battery performance.

The research reported in this publication was supported by funding from King Abdullah University of Science and Technology (KAUST).

${ }^{1}$ Y. Jing, Z. Zhou, C. R. Cabrera, and Z. Chen, "Graphene, inorganic graphene analogs and their composites for lithium ion batteries," J. Mater. Chem. A 2, 12104-12122 (2014).

${ }^{2}$ W. Sun and Y. Wang, "Graphene-based nanocomposite anodes for lithium-ion batteries," Nanoscale 6, 11528-11552 (2014).

${ }^{3}$ H. Kang, Y. Liu, K. Cao, Y. Zhao, L. Jiao, Y. Wang, and H. Yuan, "Update on anode materials for Na-ion batteries," J. Mater. Chem. A 3, 17899-17913 (2015).

${ }^{4}$ M. V. Reddy, G. V. S. Rao, and B. V. R. Chowdari, "Metal oxides and oxysalts as anode materials for Li ion batteries," Chem. Rev. 113, 5364-5457 (2013).

${ }^{5}$ K. Fukuda, K. Kikuya, K. Isono, and M. Yoshio, "Foliated natural graphite as the anode material for rechargeable lithium-ion cells," J. Power Sources 69, 165-168 (1997).

${ }^{6}$ J. Zhang, L. Chang, F. Wang, D. Xie, Q. Su, and G. Du, "Ultrafine $\mathrm{SnO}_{2}$ nanocrystals anchored graphene composites as anode material for lithiumion batteries," Mater. Res. Bull. 68, 120-125 (2015).

${ }^{7}$ Z.-S. Wu, W. Ren, L. Wen, L. Gao, J. Zhao, Z. Chen, G. Zhou, F. Li, and H.-M. Cheng, "Graphene anchored with $\mathrm{Co}_{3} \mathrm{O}_{4}$ nanoparticles as anode of lithium ion batteries with enhanced reversible capacity and cyclic performance," ACS Nano 4, 3187-3194 (2010).

${ }^{8}$ G. A. Tritsaris, E. Kaxiras, S. Meng, and E. Wang, "Adsorption and diffusion of lithium on layered silicon for Li-ion storage," Nano Lett. 13, 2258-2263 (2013).

9 J. Qian, X. Wu, Y. Cao, X. Ai, and H. Yang, "High capacity and rate capability of amorphous phosphorus for sodium ion batteries," Angew. Chem. Int. Ed. 52, 4633-4636 (2013).

${ }^{10}$ J. Sun, H.-W. Lee, M. Pasta, H. Yuan, G. Zheng, Y. Sun, Y. Li, and Y. Cui, "A phosphorene-graphene hybrid material as a high-capacity anode for sodium-ion batteries," Nat. Nanotechnol. 10, 980-985 (2015).

${ }^{11}$ B. Xu, D. Qian, Z. Wang, and Y. S. Meng, "Recent progress in cathode materials research for advanced lithium ion batteries," Mater. Sci. Eng., R 73, 51-65 (2012).

${ }^{12}$ X. Xiang, K. Zhang, and J. Chen, "Recent advances and prospects of cathode materials for sodium-ion batteries," Adv. Mater. 27, 5343-5364 (2015).

${ }^{13}$ X. Tan, C. R. Cabrera, and Z. Chen, "Metallic BSi ${ }_{3}$ silicene: A promising high capacity anode material for lithium-ion batteries," J. Phys. Chem. C 118, 25836-25843 (2014).

${ }^{14}$ V. V. Kulish, O. I. Malyi, C. Persson, and P. Wu, "Phosphorene as an anode material for Na-Ion batteries: A first-principles study," Phys. Chem. Chem. Phys. 17, 13921-13928 (2015).

${ }^{15}$ B. Ahmed, D. H. Anjum, M. N. Hedhili, and H. N. Alshareef, "Mechanistic insight into the stability of $\mathrm{HfO}_{2}$-coated $\mathrm{MoS}_{2}$ nanosheet anodes for sodium ion batteries," Small 11, 4341-4350 (2015).

${ }^{16}$ H. Shu, F. Li, C. Hu, P. Liang, D. Cao, and X. Chen, "The capacity fading mechanism and improvement of cycling stability in $\mathrm{MoS}_{2}$-based anode materials for lithium-ion batteries," Nanoscale 8, 2918-2926 (2016).

${ }^{17}$ S. Cahangirov, M. Topsakal, E. Aktürk, H. Şahin, and S. Ciraci, "Twoand one-dimensional honeycomb structures of silicon and germanium," Phys. Rev. Lett. 102, 236804 (2009).

${ }^{18}$ Y. Liao, K.-S. Park, P. Xiao, G. Henkelman, W. Li, and J. B. Goodenough, "Sodium intercalation behavior of layered $\mathrm{Na}_{\mathrm{x}} \mathrm{NbS}_{2}$ $(0 \leq x \leq 1)$," Chem. Mater. 25, 1699-1705 (2013).

${ }^{19}$ D. Er, J. Li, M. Naguib, Y. Gogotsi, and V. B. Shenoy, "Tii $\mathrm{C}_{2} \mathrm{MXene}$ as a high capacity electrode material for metal ( $\mathrm{Li}, \mathrm{Na}, \mathrm{K}, \mathrm{Ca})$ ion batteries," ACS Appl. Mater. Interfaces 6, 11173-11179 (2014).

${ }^{20}$ Y. Xie, Y. DallAgnese, M. Naguib, Y. Gogotsi, M. W. Barsoum, H. L. Zhuang, and P. R. C. Kent, "Prediction and characterization of MXene nanosheet anodes for non-lithium-ion batteries," ACS Nano 8, 9606-9615 (2014).

${ }^{21}$ R. Lv, J. A. Robinson, R. E. Schaak, D. Sun, Y. Sun, T. E. Mallouk, and M. Terrones, "Transition metal dichalcogenides and beyond: Synthesis, properties, and applications of single- and few-layer nanosheets," Acc. Chem. Res. 48, 56-64 (2015). 
${ }^{22}$ E. Yang, H. Ji, and Y. Jung, "Two-dimensional transition metal dichalcogenide monolayers as promising sodium ion battery anodes," J. Phys. Chem. C 119, 26374-26380 (2015).

${ }^{23}$ A. K. De, A Textbook of Inorganic Chemistry (New Age International, 2003), p 155.

${ }^{24} \mathrm{G}$. Kresse and D. Joubert, "From ultrasoft pseudopotentials to the projector augmented-wave method," Phys. Rev. B 59, 1758-1775 (1999).

${ }^{25}$ J. P. Perdew, K. Burke, and M. Ernzerhof, "Generalized gradient approximation made simple," Phys. Rev. Lett. 77, 3865-3868 (1996).

${ }^{26}$ S. Grimme, J. Antony, S. Ehrlich, and H. A. Krieg, "Consistent and accurate $a b$ initio parametrization of density functional dispersion correction (DFT-D) for the 94 elements H-Pu," J. Chem. Phys. 132, 154104 (2010).

${ }^{27}$ G. Mills, H. Jónsson, and G. K. Schenter, "Reversible work transition state theory: Application to dissociative adsorption of hydrogen," Surf. Sci. 324, 305-337 (1995).
${ }^{28} \mathrm{~K}$. Abraham, M. Rupich, and J. Elliot, "Rechargeable sodium batteries-VI. Cycling behavior of $\mathrm{VS}_{2}, \mathrm{VCl}_{3}+\mathrm{nS}$ ' and $\mathrm{NbS}_{2} \mathrm{Cl}_{2}$ cathodes in molten $\mathrm{NaAlCl}_{4}$," Electrochim. Acta 30, 1635-1643 (1985).

${ }^{29}$ R. V. Kumar and T. Sarakonsri, High Energy Density Lithium Batteries (Wiley-VCH, 2010), pp. 1-25.

${ }^{30}$ F. Zhou, M. Cococcioni, C. A. Marianetti, D. Morgan, and G. Ceder, "First-principles prediction of redox potentials in transition-metal compounds with LDA+U," Phys. Rev. B 70, 235121 (2004).

${ }^{31}$ J. Sun, A. Ruzsinszky, and J. P. Perdew, "Strongly constrained and appropriately normed semilocal density functional," Phys. Rev. Lett. 115, 036402 (2015).

${ }^{32}$ I. G. Buda, C. Lane, B. Barbiellini, A. Ruzsinszky, J. Sun, and A. Bansil, "Characterization of thin film materials using SCAN MetaGGA, an accurate nonempirical density functional," Sci. Rep. 7, 44766 (2017). 